\title{
Ascending aortitis and aortic valve endocarditis in an infant
}

\author{
Dilip S. Nath, MD, Angela J. Shin, BS, Daniel P. Nussbaum, BS, Darren Berman, MD, \\ Vaughn A. Starnes, MD, and Winfield J. Wells, MD, Los Angeles, Calif
}

Aortic valve replacement for endocarditis in infancy is problematic. The Ross procedure is the best alternative, but in the face of an extensively infected ascending aorta requiring prosthetic extension of an autograft, a therapeutic dilemma is present. ${ }^{1}$ Palliation with an aortic homograft for root and ascending aortic replacement until infection is resolved offers an alternative approach.

\section{CLINICAL SUMMARY}

A 5-month-old boy presented with fever, tachycardia, and a systolic heart murmur. At 1 month of age, he had been treated for congenital aortic stenosis (AS) with balloon aortic valvoplasty. Six weeks before the present illness, a catheterization was performed to assess the residual left ventricular outflow tract gradient and pulmonary vascular bed. During the procedure, there was no suspicion of an intimal tear or dissection. This study and a subsequent echocardiogram showed mild AS and trace aortic insufficiency. After a lumbar puncture, antibiotics were initiated for a presumptive diagnosis of meningitis. Two days later, there was seizure activity, and imaging showed a subacute infarction in the right middle cerebral artery distribution. Blood culture results were positive for Enterococcus faecalis.

An echocardiogram revealed thickened aortic valve leaflets with vegetation adjacent to the left cusp and an abnormal appearance of the ascending aorta, suggesting aortitis with intraluminal hematoma, dissection, or pseudoaneurysm. Brain magnetic resonance imaging demonstrated an evolving infarction in right middle cerebral artery distribution. The patient was seizure free and had no focal neurologic findings. Surgical intervention was planned to replace the aortic valve and ascending aorta.

At the time of the operation, the entire ascending aorta appeared thickened and inflamed (Figures 1 and 2). Aortic cannulation was performed more distal than usual in the transverse arch to allow for high aortic crossclamp place-

From the Childrens Hospital Los Angeles, Keck School of Medicine, University of Southern California, Los Angeles, Calif.

Disclosures: None.

Received for publication Nov 24, 2008; revisions received March 25, 2009; accepted for publication April 27, 2009.

Address for reprints: Vaughn A. Starnes, MD, Childrens Hospital Los Angeles, Division of Cardiothoracic Surgery, 4650 Sunset Blvd, MS 66, Los Angeles, CA 90027 (E-mail: vstarnes@chla.usc.edu).

J Thorac Cardiovasc Surg 2010;139:e90-1

$0022-5223 / \$ 36.00$

Copyright (c) 2010 by The American Association for Thoracic Surgery doi:10.1016/j.jtcvs.2009.04.030

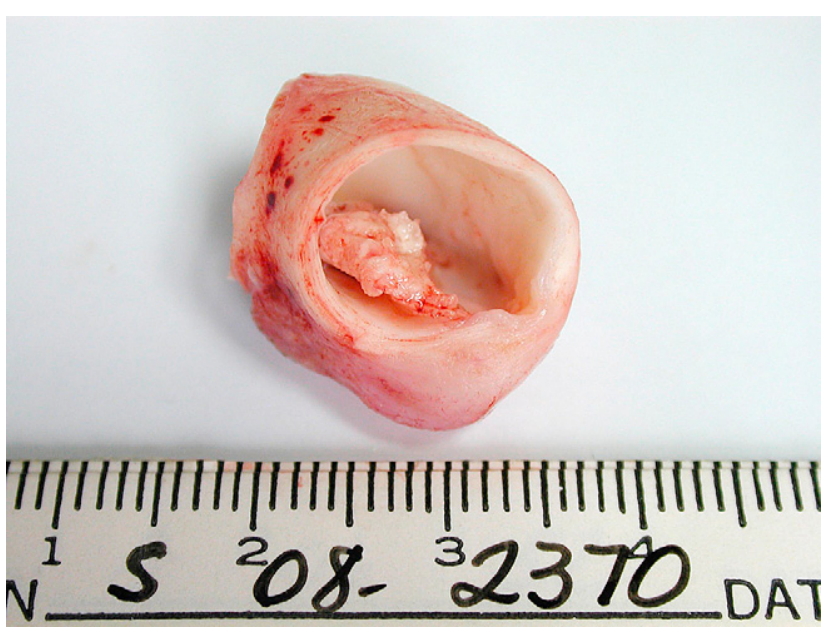

FIGURE 1. Gross image of the aorta showing irregular mural vegetation adjacent to an area of mural necrosis and early aneurysm formation. (Original magnification, $1.5 \times$.)

ment. By using a handheld cannula, cardioplegia was administered directly into the coronary ostia. When the aorta was opened, there was a large vegetation adherent to the aortic wall extending from the sinotubular junction to the innominate artery takeoff. A separate vegetation was found on the left coronary leaflet of the aortic valve. An 11-mm aortic homograft was used for root and ascending aortic replacement with the distal anastomosis at the innominate artery takeoff. Bypass and crossclamp times were 40 and 29 minutes, respectively.

The patient was discharged after a 1-week hospital stay and was treated with an additional 5 weeks of outpatient intravenous antibiotics. He was followed with serial echocardiograms. Five months after root replacement, the patient experienced supravalvar stenosis of the ascending aorta and underwent balloon dilatation. After an additional 4 months, the patient had evidence of progressive AS, aortic insufficiency, and supravalvar homograft stenosis. He underwent a Ross procedure and was discharged uneventfully after a 5-day hospital stay. He continues to do well 1 month after surgical intervention.

\section{DISCUSSION}

If aortic valve replacement is required in an infant, particularly in the presence of active endocarditis, a tissue valve offers the best option. ${ }^{2}$ The Ross procedure provides optimal hemodynamics, freedom from anticoagulation, probability 


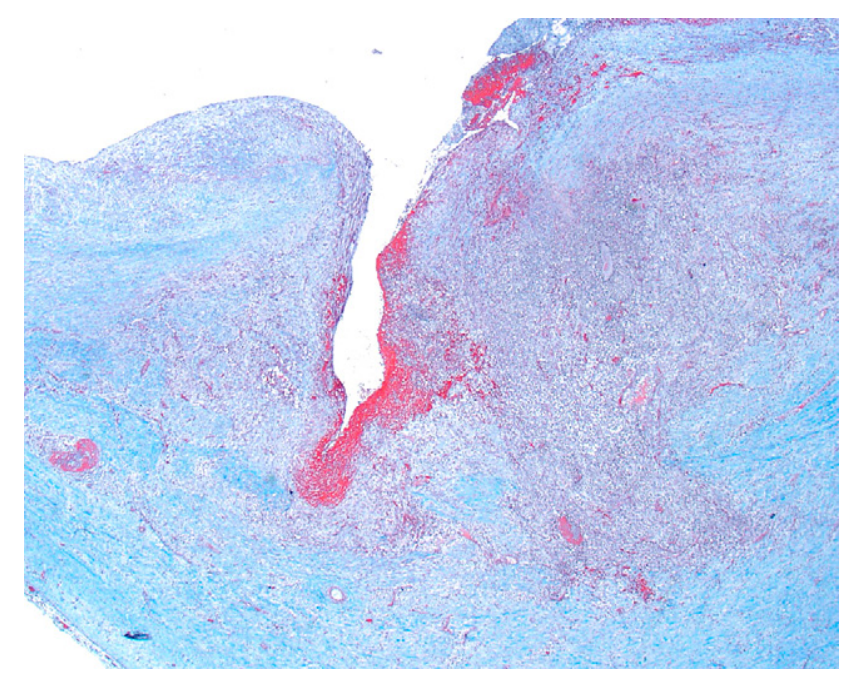

FIGURE 2. Trichrome staining of the aortic aneurysm shows red blood cell infiltration of the aortic wall. Colonies of gram-positive cocci are stained red. (Original magnification, $20 \times$.)

of a low rate of reinfection, durability, and potential for growth. ${ }^{3}$ There is concern that if the autograft were to become infected, then the optimal valve for the long-term might be wasted. An alternative would be to use an aortic homograft in what amounts to a palliative first stage of a 2-stage approach. Although offering all of the advantages of a stentless bioprosthesis, the durability of aortic homografts has been very limited in infants and young children. ${ }^{4}$ Use of a homograft would be directed at eliminating the risk of autograft reinfection, saving that valve for later implantation when infection has cleared and homograft replacement is required.
A confounding problem is the presence of ascending aortitis in conjunction with aortic valve endocarditis. This highly unusual condition requires replacement of the entire ascending aorta and thus complicates a Ross procedure because the pulmonary autograft would require prosthetic extension. Such an extension might increase the risk of reinfection, severely limit the durability of the Ross repair by virtue of a lack of growth potential, or both. Hence the aortic homograft becomes the best choice, with expectation that the Ross procedure would be performed at time of homograft failure. We predicted that the homograft would last 1 year or less based on prior experience. The primary concern for use of an autograft at the initial procedure was infection that might compromise the best long-term valve replacement option for this infant. Many of our pediatric patients undergoing the Ross procedure have had previous operations, including an aortic root replacement, and risk of reoperation in this population has been low. Aortic homograft implantation has been reported in the setting of acute aortitis in 2 children. $^{5}$

\section{References}

1. Birk E, Sharoni E, Dagan O, Gelber O, Georghiou GP, Vidne BA, et al. The Ross procedure as the surgical treatment of active aortic valve endocarditis. J Heart Valve Dis. 2004;13:73-7.

2. Kilian E, Oberhoffer M, Gulbins H, Uhlig A, Kreuzer E, Reichart B. Ten years experience in aortic valve replacement with homografts in 389 cases. J Heart Valve Dis. 2004;13:554-9.

3. Kouchoukos NT, Davila-Roman VG, Spray TL, Murphy SF, Perrillo JB. Replacement of the aortic root with a pulmonary autograft in children and young adults with aortic-valve disease. N Engl J Med. 1994;330:1-6.

4. Kaya A, Schepens MA, Morshuis WJ, Heijmen RH, Brutel de la Riviere A, Dossche KM. Valve-related events after aortic root replacement with cryopreserved aortic homografts. Ann Thorac Surg. 2005;79:1491-95.

5. Raff GW, Gray BM, Torres A Jr, Hasselman TE. Aortitis in a child with Abiotrophia defectiva endocarditis. Pediatr Infect Dis J. 2004;23:574-6.

\title{
An unusual tumor of the esophagus
}

\author{
George Rakovich, MD, Denise Ouellette, MD, and Gilles Beauchamp, MD, Montreal, Quebec, Canada
}

Carcinosarcoma of the esophagus is a very rare tumor that has both epithelial and mesenchymal (sarcomatous) components. The points of interest in the presented case are the

\footnotetext{
From the Division of Thoracic Surgery, Hôpital Maisonneuve-Rosemont, University of Montreal, Montreal, Quebec, Canada.

Disclosures: None.

Received for publication Oct 30, 2008; accepted for publication Nov 19, 2008.

Address for reprints: George Rakovich, MD, Division of Thoracic Surgery, Hôpital

Maisonneuve-Rosemont, Montreal, Quebec H1T 2M4, Canada (E-mail: george.

rakovich@umontreal.ca).

J Thorac Cardiovasc Surg 2010;139:e91-3

$0022-5223 / \$ 36.00$

Copyright (C) 2010 by The American Association for Thoracic Surgery

doi:10.1016/j.jtcvs.2008.11.075
}

osteosarcomatous nature of the mesenchymal component, as well as the early and massive recurrence after esophagectomy despite an early pathologic stage, reflecting the fastgrowing and potentially aggressive nature of these tumors.

\section{CLINICAL SUMMARY}

A 70-year-old man presented with progressive dysphagia to solid food, which he localized at the level of the midesophagus. He was an active smoker with a professional exposure to asbestos over a period of 25 years, and his medical history included hypercholesterolemia and a T3 N0 prostate cancer currently in remission after radiotherapy. Initially, he had had an acute episode of chest pain immediately after 